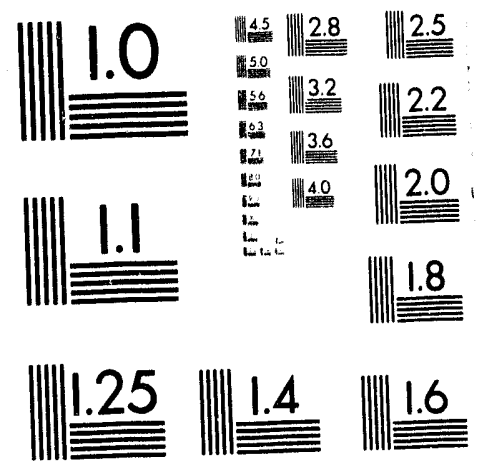



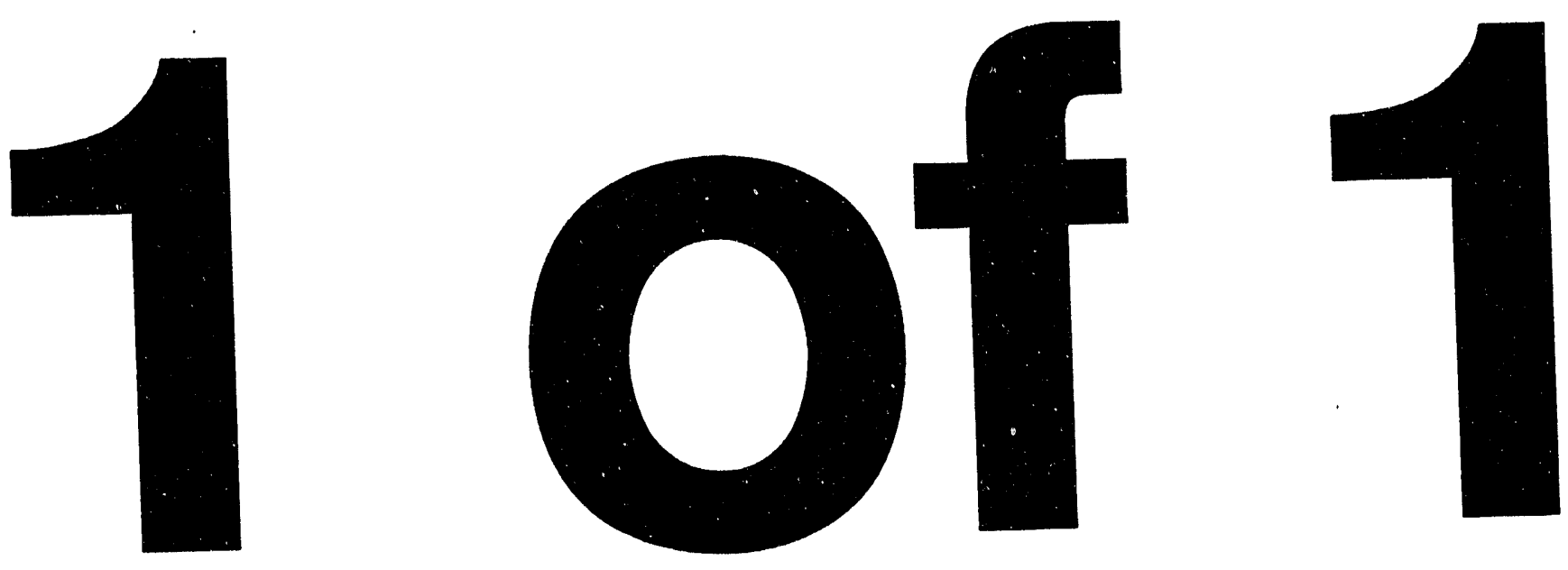
SAND94-8218

UC-406

Unlimited Distribution

February 1994

\title{
PATHWAYS TO AGILITY IN THE PRODUCTION OF NEUTRON GENERATORS
}

\author{
R. E. Stoltz \\ Sandia National Laboratories / California \\ L. C. Beavis \\ J. T. Cutchen \\ P. Garcia \\ G. A. Gurule \\ R. N. Harris \\ P. C. McKey \\ D. W. Williams \\ Sandia National Laboratories / New Mexico
}

\begin{abstract}
This report is the result of a study team commissioned to explore pathways for increased agility in the manufacture of neutron generators. As a part of Sandia's new responsibility for generator production, the goal of the study was to identify opportunities to reduce costs and increase flexibility in the manufacturing operation. Four parallel approaches (or pathways) were recommended: (1) Know the goal, (2) Use design leverage effectively, (3) Value simplicity, and (4) Configure for flexibility. Agility in neutron generator production can be enhanced if all of these pathways are followed. The key role of the workforce in achieving agility was also noted, with emphasis on ownership, continuous learning, and a supportive environment.
\end{abstract}




\section{CONTENTS}

I. Introduction

Page No.

II. Agile Manufacturing 8

$\begin{array}{ll}\text { III. Pathways } & 10\end{array}$

$\begin{array}{ll}\text { N. The Work Force } & 19\end{array}$

$\begin{array}{ll}\text { V. Summary } & 20\end{array}$

Appendix A: Presentavion Briefing Notes 27

Appendix B: Quotes and Observations 51 


\section{PATHWAYS TO AGILITY IN THE PRODUCTION OF NEUTRON GENERATORS}

\section{Introduction}

In April 1993, the Neutron Generator Manufacturing Facility (NGMF) Advanced Manufacturing Study Team was formed. The team was sponsored by Gary Beeler and Harry Saxton and was asked to:

Conduct a short-term study to identify advanced manufacturing concepts applicable to neutron generator production.

In addition to Beeler and Saxton, other key stakeholders in the study results were John Gronager and Jimmy Searcy. Eight team members were chosen for the assignment, which was scoped as a six-week study. Team members were picked for their technical backgrounds and interests and for their creative and "out of the box" thinking skills. Members included:
L. C. Beavis, 2471
R. N. Harris, 2604
J. T. Cutchen, $25 \mathrm{CS}$
P. C. McKey, 2486
P. Garcia, 1671
R. E. Stoltz, 8008
G. A. Gurule, 325
D. W. Williams, 2304

Initial team meetings with the sponsor and key stakeholders focused on clarifying the mission and scope of the group's activities, on addressing concerns and on the mechanics of information gathering, synthesis, and reporting.

Mission: The mission of the NGMF Advanced Manufacturing Study Group was developed by the team members and was used to guide this study. The mission was:

To describe workable pathwavs by which SNL can improve its operations and business practices to reduce costs and increase flexibility in the NGMF.

Concerns: The team addressed concerns and sought to remedy these at the outset. Table 1 summarizes the team's issues as well as the remedies that were adopted.

Mechanics: The study team negotiated with the study sponsors, Gary Beeler and Harry Saxton, for a May 19, 1993, date to complete the study. The team agreed to a presentation briefing and discussion session as well as a white paper describing in greater detail the observations, suggestions, and recommendations of our study. The 
team used various internal documents, books, and articles from the literature to understand both the details of the proposed Neutron Generator Manufacturing Facility as well as modern aspects of lean manufacturing, agility, and quality. A list of references is included with this report. The team held meetings on 15 contact days from April 14 through May 19. In addition, two site visits were made:

- Varian Power Grid \& X-Ray Tube Products, San Carlos, CA (April 28, 1993)

- Martin Marietta Specialty Components, Pinellas Plant, Largo, FL (May 6-7, 1993)

Observations, suggestions, issues, and ideas were collected by each team member. The main work of the team was to group, evaluate, and organize these ideas into pathways or approaches and to enlarge on these pathways with concrete suggestions for actions that Sandia might take to reduce costs and increase flexibility.

In order to provide a background for further discussion, the next section is a short tutorial on agile manufacturing concepts, taken largely from the lacocca Institute, Agile Manufacturing Enterprise Forum, at Lehigh University.

\section{Agile Manufacturing}

Over the last 100 years, manufacturing systems have evolved to meet changes in customer demand, to improve efficiency and profitability, and to take advantage of emerging technologies both on and above the factory floor. The evolution in these systems is shown schematically in Figure 1. Starting in the late-1800s, mass production systems were developed. These are typlified by large production runs, large in-process inventories, a "push" flow of work through the facility and, most importantly, a system organized to "build and warehouse" finished goods. The quantities to be produced in a mass production system are based on market predictions.

Starting in the 1970s, a jean production approach was adopted. Also called "Just-inTime," the characteristics are smaller inventories and less work-in-progress. A "kanban" system is used to "pull" work through the facility; that is, the completion of components and/or depletion of subcomponents triggers a call to start fabricating more subcomponents. In this way, the completion of products is a signal to pull more work through the plant. One advantage of JIT is the cost savings that resulted from fewer materials and goods in inventory. More importantly, marked improvements in quality, less scrap, and less rework results from the smaller batches and more instantaneous discovery of defects that accompanies lean production systems. As with mass production, the quantities of products to be produced are sized to meet market projections.

More recently, the overarching concept of agile manufacturing has emerged. In this approach, production lot sizes may approach quantities of one, there is very little idle work-in-progress and no in-process inventories. The "kanban" system is used to "pull" the work through the production line. The differentiating features of agile systems are 
that units are built to order from customer inputs and that the available variety of features is wide enough to satisfy a wide range of customer wants and needs.

Agile Enterprise Characteristics." The Agile Manufacturing Enterprise Forum has published extensive reports, treatises and position papers on the characteristics of an agile enterprise. There are two perspectives one can take to view these characteristics: the outsider's view looking into the enterprise and the insider's view looking at his or her own company.

From the outside, a customer sees the rapid roll-out of new consumer products with a variety of customizable feature. Over time, the product features can be modified by sending the item back to the company for upgrades. This is opposed to a "model change" where the previous model is discarded. Because of this upgradability concept, the relationship between the customer and the enterprise is long term. Finally, the customer is charged (and is willing to pay) for a combination of valueadded products, services, and information that the enterprise provides. Since this value-added combination is different for different customers, the overall price paid may not be the same for all customers.

From the inside looking in, the key characteristic of an agile enterprise is people. making optimal use of technology to achieve enterprise objectives. Company resources, management, and the infrastructure are geared and focused on supporting the creativity of the work force. Across all levels of the enterprise, there is mutual responsibility for success. Work functions are distributed among teams and the teams are connected by "groupware" tools.

Within the agile enterprise, decisions are made at the lowest organizational level possible and always at the point (in space and time) where the information is generated. The production machinery is flexible and supports the work force in their attempt to produce customized, quality products. On any given day, suppliers may be present and active in product design and often there is extensive cooperation with competitors' personnel on joint projects.

Agility Benchmarking and Self-Assessment Areas." The Agile Manufacturing Enterprise Forum Focus Group on Benchmarking and Self-assessment has developed a framework for measuring an enterprise's approach to agility. This self-assessment is often coupled with the National Center for Manufacturing Science's (NCMS) lean production benchmarking tool, since the two are complementary.

The agility benchmarking group has identified five questions for assessment. These questions focus on the most critical aspects of an enterprise as it strives to become more agile.

1. Is product development based on the customer's criteria of adding value?

\footnotetext{
* Goldman, S. L. and Nagel, R. N. in Intl. J. of Technology Manazement. Vol. 8, Nos. 1/2, 1993

** 2nd Annual AMEF Conference Proceeding, Vol. 2, 1991.
} 
2. Does the enterprise enhance the impact of people on their ability to accomplish agile product realization?

3. Are enterprise resources leveraged through cooperation with other companies?

4. Are the enterprise resources organized to use change and uncertainty as growth opportunities?

5. Does the enterprise incorporate ethical and social values in decision making?

These questions can be used to determine the extent of agility in any organizationnot exclusively those involved in manufacturing.

\section{Pathways}

The mission of the study group was to describe workable pathways or approaches to reduce costs and to improve flexibility in the proposed Neutron Generator Manufacturing Facility. The facility is being established at Sandia National Laboratories, New Mexico. Since the goal of the facility is to produce defense, rather than consumer products, and since the operations and business practices are still in the design stage, the team did not restrict itself solely to the agility characteristics listed above. Rather, the team attempted to incorporate the best and most important practices from mass production, lean production, and agility in developing these pathways.

Early in the study, it became clear that the concept of balance was critical in order to achieve cost reduction and flexibility. This balance is reflected in Figure 2, where both operations and business practices are considered. From the outset, the team felt it important to emphasize that attention to one over the other is detrimental in achieving a fully optimized enterprise.

Four pathways were identified as critical to achieving agility in the Neutron Generator Manufacturing Facility. They are:

- KNOW THE GOAL

- USE DESIGN LEVERAGE EFFECTIVELY

- VALUE SIMPLICITY

- CONFIGURE FOR FLEXIBILITY

The interrelationship of these pathways is shown schematically in Figure 3. Within the context of the goal of the enterprise, the intersection set of simplicity, flexibility, and design leverage is the pathway to agility (Figure 3a). Specific examples-not a complete list-of how we have already begun to exploit these pathways are indicated in Figure 3b. Once the goal is well established and all of these pathways are integrated, a fully agile enterprise will result. 


\section{Pathway No. 1: "Know The Goal"}

This pathway is the key enabler to achieving agility in the NGMF. It is by complete knowledge and understanding of the goal that one is able to facilitate decisions and select program/process alternatives. It is from this goal that one will establish the metrics by which progress is measured.

The team suggested a simple three-step process to convert knowledge of the goal into action:

STEP 1: WRITE a single statement of the enterprise's goal.

STEP 2: Determine which operation and business practice METRICS can be used to MEASURE progress towards this goal.

STEP 3: Establish written criteria for decision making which are based upon these METRICS and can be applied SIMULTANEOUSLY in the decision making process.

\section{Step 1: Write the Goal}

It is very important to write the goal as a simple statement that clearly articulates the reason for the enterprise's existence and promotes a consensus view throughout the enterprise. A common trap is that the goal becomes a series of goals linked together. Such a practice can lead to conflicting decision criteria, loss of focus in the management of the enterprise, and intra-organizational strife as various groups can each invoke elements of the written goal as justification for their views and actions.

\section{Step 2: Establish Motrics}

A clearly written goal should contain a small set of metrics by which to manage the enterprise. In Appendix A, charts 17 through 19, three examples of the establishment of metrics based on three different written goals are shown.

As shown in Appendix A, chart 19, "A Sandia Example," a hypothetical written goal could be:

"Operate a facility of national strategic impentance for the fabrication of neutron generators and switch tubes at a minimum total cost."

In this example, the phrases "national strategic importance" and "total cost" are underscored to highlight that it is in these phrases that the metrics have their origins. The question is asked, "What does the nation expect SNL to do in order to ensure its defense capability?" The answer to this hypothetical example is that Sandia is to manufacture products that perform at the required level and deliver them in a timely manner. In this response is found the first two metrics:

Metric 1: Product Performance 
Metric 2: Schedule Variance

Both of these metrics have two key properties. They are physical observables for the enterprise and they have their genesis in the written goal statement.

The third metric in the example is born from the "minimum total cost" phase, and is stated as simply

\section{Metric 3: Total Cost}

Note that the goal is not minimum indirect-to-direct cost or some other likely enterprise objective. The metric is born of the written goal statement and is stated directly as total cost. Failure to establish the appropriate metrics can lead to mismanagement of the enterprise. As such, metrics should be viewed as the framework by which the enterprise management will be organized and the results measured.

\section{Step 3: Write Goal-Based Decision Criteria}

Once the goal and metrics are stated and understood, one can proceed to write goalbased decision criteria for operation. These goal-based decision criteria ask whether a proposed action will simultaneously improve the metrics and, more importantly, support meeting the written goal.

In the example being discussed, application of the goal-based criteria leads to the question,

\footnotetext{
Will this pending action SIMULTANEOUSLY

- improve our product's performance,

- reduce our schedule variance, and

- reduce our total cost?
}

Note that we highlight the word "simultaneously" in this written goal-based decision criteria statement. This is done as a reminder that for a positive or "go" decision to be made the action must move the enterprise simultaneously forward toward improvement in all three metrics. (In this sense, a "null effect" is considered a positive result for the decision-making process.) Simultaneity is an imposed condition to prevent one from optimizing one enterprise metric at the expense of the others ("local optimization").

Through shared understanding of the written goal, everyone in the enterprise knows why it exists. From its mutually understood metrics, everyone may observe how the enterprise is proceeding toward its written goal. Finally, by consistently basing decisions upon simultaneous consideration of established criteria, a healthy enterprise can move along the pathways toward success in a steady, participative manner. 


\section{Pathway No. 2: "Use Deslan Leverage Effectively"}

During the evolution and manufacture of a new product, the smallest cost element is usually the product design phase. However, the design phase has the highest leverage upon total cost during the life cycle of the product. Not only product performance features, but all aspects of assembly and piece-part definition, as well as the processes that enable piece-part fabrication and assembly are governed by the design. In fact, the design ultimately drives all manufacturing-related precesses and this large leverage mus: be used effectively.

Understanding the customer's requirements is a fundamental tenet of the design process. However, real design effectiveness occurs when the reasons behind requirements are also known. This mandates consultation with the customer, whereby the boundary conditions and constraints of the product, as well as the unwritten wants and needs of the customer can be determined. Early institution of this consultative process can also lead to additional features or benefits that provide added value for the customer with minimal cost and investment. By corollary, when there are cost and/or operational constraints that limit the customer's options, this information must be shared with the customer. Key design parameters should reflect the critical requirements. Critical design characteristics should be integrated effectively with critical manufacturing processes. In all cases, the final requirements must represent a negetiated position, where the needs and constraints of both sides, customer and supplier, are reflected in a win-win result. The design function must be managed and carried out with discipline and careful attention to critical guidelines. Some of these are outlined below:

Maintain design stability and discipline. The standardization of components, subassemblies and final assemblies leads to cost reductions and improved product reliability and yield. This also enhances simplicity in the manufacturing facility. To facilitate this concept, however, the baseline design of the standard product must have a sufficiently wide performance envelope to meet a broad spectrum of requirements. This principle is exemplified by the MC4277 neutron tube, the building block of nextgeneration neutron generator designs. This tube is capable of neutron rates 100 times higher than those in conventional WR neutron generators. Thus, by tailoring neutron generator design and packaging features, this single tube will support a wide variety of applications, ranging from nuclear weapon WR components to specialized field test needs. (Its follow-on, the smaller MC4300 neutron tube, will permit packaging in smaller neutron generators and is expected to ultimately become the standard tube for future applications.) To reinforce design stability and discipline, cost-benefit analyses must be considered before making significant design changes, and marginal design benefits that diverge from simplicity should be eliminated.

Emphasize concurrent engineering and design for manufacturability. As the product design matures it must be optimized for manufacturability. This requires that concurrent engineering be implemented. Beginring early in the design process, the design engineer must coordinate design details with the manufacturing engineer and with process and materials engineers. When product and process engineering 
proceed concurrently, design simplification to reduce total parts count, the manufacture of piece parts, subassemblies, and the final assembly are key considerations. To be effective, the processes and equipment that will be used in the manufacturing facility must be characterized beforehand. The design and manufacturing engineers must then ensure that the product can be manufactured by operating within the capability of the equipment and processes. In some cases, features may be incorporated in piece parts that will increase up-front costs, but will greatly simplify assembly and decrease scrap downstream when the assemblies have significant added value. The principles of concurrent engineering and design for manufacturability should be a central theme of a rigorous design review process, involving multiple design reviews covering all phases from concept to post-production.

\section{Keep only essential specifications and emphasize industrial}

specifications. At the current production facility for neutron generators (Pinellas Plant), a large inventory of specialized specifications was established for development of components that have never achieved production. These specifications are still in the archives. Only the specifications essential to the processes being transferred to Sandia should be retained. Industrial specifications should be used whenever possible. Once drawings, specifications, Operating Instructions (O/s), etc., are issued, they must be periodically validated against actual procured materials and products to determine the need for updates and to account for variations that may have crept in over time from the originally-specified products.

\section{Seek commonality of plece parts and processes for Switch Tubes,} Neutron Tubes, and Neutron Generators. To reduce inventories and minimize costs, common piece parts and standardized processes should be employed as much as possible. Where actual parts may not be interchangeable across the three families of Switch Tubes, Neutron Tubes, and Neutron Generators, the use of common materials should still be maximized.

\section{Pathway No. 3: "Value Simplicity"}

Simplicity in design, materials, and processes will minimize overall cost by reducing processing steps, handling, storage, and piece parts. In addition, product robustness will increase because of fewer chances for errors, great or small, by humans or machines.

Simplicity occurs through designing to meet agreed goals of the product. On occasion, a design requirement may preclude achieving the maximum in simplicity. For example, limits on the allcwed hydrogen permeation (a lifetime issue) through the envelope of a neutron tube dictate the use of either Kovar-copper-Kovar Tri-Clad sheet or a material such as molybdenum. This, in turn, makes assembly more complex and less tolerant of errors in piece-part fit or in the cleaning and joining processes. Simplicity, taking into account the materials constraints, clearly should be maximized in any case. 
Simplicity and flexibility often go together, but not always. For example, the original gas discharge neutron tubes used a small metal reservoir and a separate metal pump to supply and control, respectively, the hydrogen-isotope pressure in the device. More recent versions of these tubes have sacrificed the flexibility of a very fast pressure response for the simplicity of a single reservoir that acts as a pump and a reservoir.

We believe that simplicity can be applied equally to the work force, quality assurance, procurement, manufacturing processes, piece part design, and facilities. There are several ways in which the work force can facilitate simplicity. For example, the people who presently build neutron tubes seldom are aware of how the tubes are employed in neutron generators. Conversely, in most instances, neutron generator builders do not have appreciation for the tube builders' craft. This suggests simplifying from the start with simple piece parts, and using a common, cross-trained work force to construct both tubes and generators.

An analogous situation exists for neutron tube and switch tube fabricators. Seldom are they the same people, although the processes and materials used are similar and in some cases identical, ө.g., cleaning and etching Kovar and copper. In this case, cross-training is clearly appropriate. It is also clear that the people that fabricate devices for development, prototyping, and production should be one and the same, rather than different individuals. Finally, excessive layers of management should be eliminated.

The quality issues addressed in DOE QC-1 should be achieved through the minimum acceptable effort required to ensure compliance. Design processes and procedures should be optimized so that over-inspection, over-documentation, and over-control will be avoided. Dedicated in-process inspectors should be eliminated.

To increase greater simplicity in the organizational structure (as well as to minimize costs), vendors should be qualified to supply acceptable-quality parts and materials at the point of manufacture. Incoming inspection should be minimized or eliminated when possible.

All common operations should be standardized. For example, the cleaning process applied to copper should be the same for all copper, no matter what its final disposition. The ceramic-metallizing process for ceramic-to-metal seals should use the same materials and firing processes, independent of the final use of the seals. Processes that do not add value to the product should be eliminated. For example, inspections that consistently have a zero reject rate or those that are followed by a later inspection with little or no value added between steps are candidates for simplification by elimination. Common processes in the component life cycle should be the same, e.g., identical joints fabricated in the prototyping, development, and manufacturing stages should use identical joining process. These commonalities of processing are clearly enhanced if the same work force performs the joining no matter what the ultimate end for the component. 
Processing is normally described by written operating instructions (Ols). In instances that lend themselves to pictures, photographs, diagrams, etc., to describe a process, the appropriate graphic should be used to simplify the description and understanding of the particular process.

Minimizing the number of piece parts per component should be a requirement in design. Fewer pieces lead to a simpler, less costly device through less handling and storage and a reduced number of ancillary processes. When possible, identical piece parts should be used in different components, as this will lead to reduced inventory and less chance for error in processing. Decisions on whether to "push" or "pull" product through the production process should be made on the basis of customer requirements, reduced cosis, and time-critical schedules.

Finally, facilities for building products, whether for prototyping, development, or production, should use common equipment for fabrication when possible. For example, common brazing furnaces and common chemical-cleaning, etching, and plating equipment should be incorporated from the start. The facilities should be laid out for optimized flow of parts through the required processes. Travel distances of pieces/subassemblies should be minimized. Automated equipment, when used, should be configured so that it is easy to operate. Multi-tasked automated equipment should be easily reconfigurable.

\section{Pathway N2. 4: "Conflaure for Flexibility"}

The concept of flexibility should be incorporated in the management structure, quality assurance and automation, and control of the Neutron Generator Manufacturing Facility.

\section{Management}

Diversify the products and anticipated customer needs. One way to reduce the impact of the facility in the unit cost of each part produced in the NGMF is to increase the size of the production run. However, this may not be possible with neutron generators. Another approach is to produce other devices that use similar processes and have similar characteristics such as high voltage, high current, and vacuum-sealed components. These include switch tubes and microwave tubes, for customers other than DOE. With this approach, one can diversify both customers and products.

Reduce in-process inventory to minimize defects and scrap. Product flow in the facility needs to be designed to minimize defects and scrap. Two ways to accomplish these goals are:

1. Use small production lots (in a "push" system) or kanban (in a "pull" system) so that when a problem occurs in a given process it does not impact a large number of parts before the problem is found and resolved. 
2. Train the work force to inspect their own work so that they can detect defects early, instead of passing bad product down the line.

Conflgure the facility to support flexibility in operations. The physical and operational layout of the facility needs to support both development and production activities. A hybrid product flow system based on "push" and "pull" needs to be evaluated for doing development (one-of-a-kind) and production. A hybrid system should extend to other every day activities such as inspection, reporting, and responding to customer needs.

\section{Qually \\ Use the production work force to build quality in from the start. Flexibility in the manufacturing arena does not only have to apply to processes, tooling, equipment, and the work force, as is usually the case. Flexibility may also be implemented in the provisions or activities used for achieving the desired level of product quality. By "pushing the quality activities down," that is to the lowest levels of the work force, one can achieve a more flexible manufacturing environment. If the operators/technicians perform source inspection, i.e., inspect their own work, the number of in-process inspections can be reduced or minimized. When independent inspections are deemed critical, the operators can be trained to inspect their fellow operators' work. In this way, the responsibility of quality is passed to the operator. Accordingly, the operators will develop a sense of pride and ownership that will positively affect the quality of their work.}

Continuously monitor process stability during production. Another pathway to a flexible operation is to move away from acceptance testing of large samples as a means of assessing the quality of the product. The assessment of product quality should be made, insofar as possible, during the realization of the product and during the fabrication of the units. Statistical tools such as SPC and $C_{p k}$ analysis would play a major role in determining the product quality. If all processes are characterized and proven to be in control, only a small sample of units will be required for testing, and only for confirmation.

Combine operational areas. In today's Nuclear Weapon Complex, development and prototype builds are typically fabricated in an area different from the production floor. In a flexible operating mode, only one area will be required, with development, prototype, and production units all being fabricated using the same process lines, stations, tooling, equipment, and operators. Operators would build all of these types of units in the same manner, i.e., the level of care, attention, and workmanship would be the same for each type of unit. The flexibility would lie in the rigor of inspection performed and amount of paper associated with each type of unit. Since the same equipment and tooling would be used for development and production, all tooling and equipment would be on a rigorous calibration schedule. The users of the data would then be confident of the results and conclusions for prototype and development as well as production units. 
By implementing the above concepts in the quality operations, flexibility in the manufacturing arena is enhanced. Reduction of inspection operations frees the inspectors to do other things or to be trained to perform processing. If operators are trained to perform inspections on other people's work, they can be flexible and crosstrained to perform several jobs as needed. Moreover, by primarily assessing quality by monitoring processes during product realization or fabrication, flexibility is provided in the quantity and types of tests required for a group of units. Finally, with various degrees of inspection rigor in a single process line and with all tooling and equipment regularly calibrated, one can achieve flexibility with increased engineering/data credibility, while manufacturing prototype, development, and production units at reduced cost.

\section{Automation}

Evolve a flexible and unified communications system. The communications system should have appropriate technology at each level of the facility to facilitate the integration and use of computers, telephones, and paper in a unified communications system. Software tools and production data should reside in compatible computing platforms. The overall communications system must enhance the sharing and flow of data in the facility.

Establish a written automation policy. The formally-derived goal of the NGMF will dictate the level of automation for the facility. The spectrum can range from islands of automation in a minimum-cost facility to a completely automated line in a "lights off" factory. A policy that dictates the level of automation must be developed once the goal of the NGMF has been established.

Lack of system flexibility has been a problem in past automation efforts. In a few cases, the hardware was the controlling factor. In others, software was completely dedicated to a specific component or mode of production, thus excluding the work cells from benefiting from subsequent improvements in technology, product, or process. New automation projects must be implemented with a common software and hardware architecture that supports system flexibility and reusability of hardware/software modules.

The best results of automation are usually obtained when the automation is designed concurrently with the product and process. Automating a bad process only makes it worse. Processes must be carefully studied, and replaced or modified if necessary, before automation is attempted. Improvements should only be installed on the production line after they have been adequately tested at the laboratory level.

Processes selected for automation cannot be justified by production volume since relatively small lots will be produced in the NGMF. For this reason, the policies governing automation should be based on the following considerations:

- Improvements in operator safety and reduction in hazard exposure.

- Improvements in quality and consistency of the product.

- Preservation of capabilities that exist only in the hands of a few individuals. 
- Reduction of process-generated wastes with the incorporation of environmentally-conscious manufacturing techniques.

- Benefits derived by automation of record-keeping for accountability, security, and regulatory compliance.

\section{The Work Force}

Agility in the workplace is achieved through an agile work force comprised of management, engineering, support elements, and the production team. When these employees are able to adapt themselves and their environment to changes in product and operational demands, agility naturally follows. A great deal of attention is currently being placed on enabling technology for agility. In contrast, in this section, we discuss enabling practices, with emphasis on decreasing total costs and increasing manufacturing flexibility. All of these practices can have a substantial impact upon worker effectiveness.

Energized empowerment. In an agile environment, action occurs very close to the initial point of information-empowerment. Empowerment is energized through increased knowledge. One way to achieve this is through hiring practices that value adaptability and through strategic learning aimed at solving the manufacturing challenges holistically rather than optimizing local solutions. Training programs used to facilitate the learning process must match the desired business practices and must be perceived by the workers as value added to their personal effectiveness and the effectiveness of their team. Tactical learning must be available for specialized applications in order to help the workers overcome unanticipated obstacles. Utilizing the experiences of colleagues can often provide needed ideas and techniques. These experiences should be viewed as cross-training events that will create knowledge and understanding in the workplace, and should be encouraged. This increased workgroup knowledge will liberate the self-motivated work force, preparing them to "take action."

Ownership. Quality in a process or product can often be improved when the participants have a sense of ownership for the process or product. We have observed that production workers who follow a product from start to finish both have and maintain an enhanced sense of ownership. Admittedly, there are processes where the worker must hand off the product to another group. However, ownership is best achieved through minimizing these "over the wall" experiences.

A highly-trained work force is required to achieve this strategy. Work group control and improvement are more effective when the workers make decisions that effect their product. An example of this is when the workers author their own Operating Instructions (Ols). Once written, the Ols can be approved by either a peer or an engineer. However, the content will become less restrictive and more focused to suit the style and needs of the individual operator. When workers write their own instructions, they are less likely to include meaningless detail that wastes computer resources and paper and shortens attention span. The Ols will contain meaningful 
information and hints that will build upon basic understanding and will have fewer than tedious details that distract thinking.

Environment. The working environment should be pleasant. Attention to color, sound, cleanliness, and interruptions all improve the worker's ability to perform quality work that includes thinking of improvements.

Self-Assessment. Work groups should be encouraged to move towards selfassessment. In this way, the work group can establish and use metrics that enable them to focus on the enterprise goal. With this increased empowerment and ownership comes the desire and responsibility to understand more aspects of the enterprise goal. Eventually, a quality product, produced on schedule at minimum cost, becomes both the goal and the accomplishment of the entire work force.

\section{Summary}

The NGMF Study Team believes that the four pathways explained in this document provide a road map and template for organizing, staffing, building, and operating a facility for producing neutron generators. Combined with a focus on the productivity and agility of the work force, the team members believe that the NGMF can serve as a model for all DOE production facilities planned for Complex 21. 
Table 1.

Concerns/lssues and Proposed Remedies for the NGMF Study Team

\section{Concerns}

Unclear statement of work

What are we supposed to do?

Is there an "answer" already?

How do we get smarter?

Multiple customers - multiple answers

\section{Remedies}

Rewrite

Use missiori statement

No

Bring in others

Identify one customer and multiple stakeholders

Should suggestions be concrete vs. conceptual

Will we have "value-added"?

Establish "hard vectors"

Use "vectors" to see

Limited experience/hackground in group

Too little time

Potential for too much retracing

What about record keeping?
Augment with documents, visits, membership

Pick up pace

Don't go back

Keep informal 
FIGURE 1.

\section{EVOLUTION OF MANUFACTURING PARADIGMS}

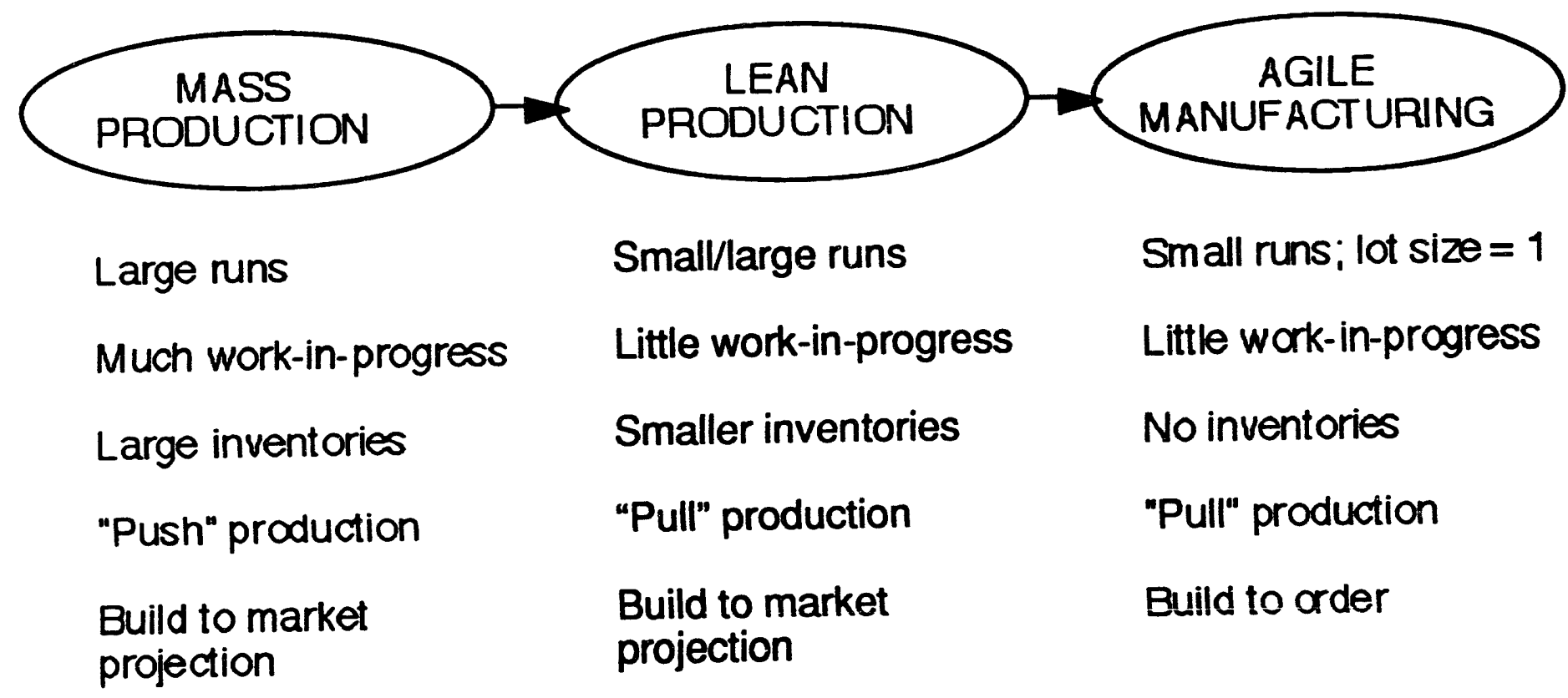


FIGURE 2.

A Balance Between Operations and Business Practices Promotes Agility

The Enterprise

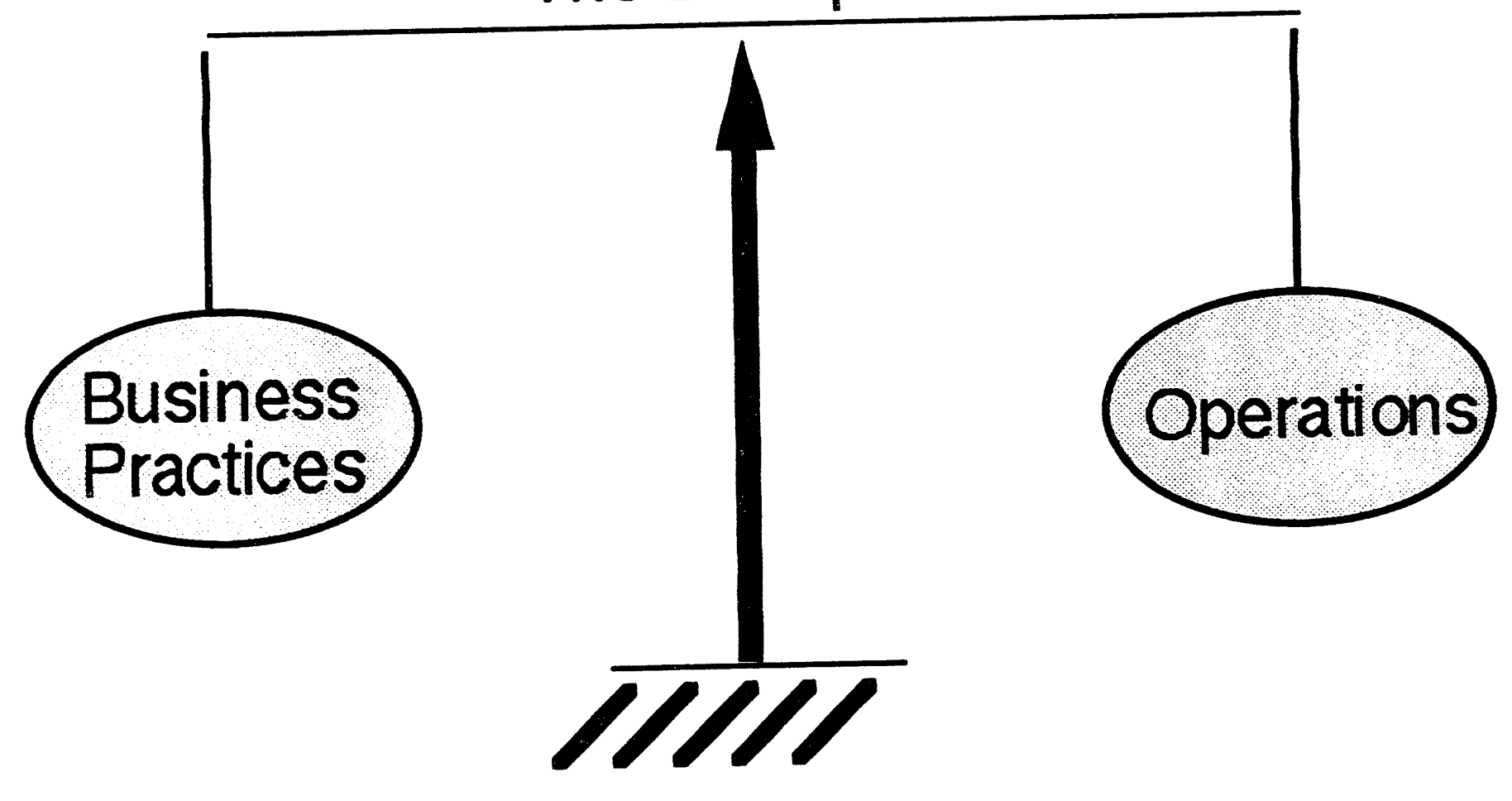


FIGURE 3.

\section{Interrelationship Between \\ Agility Pathways}

(a)

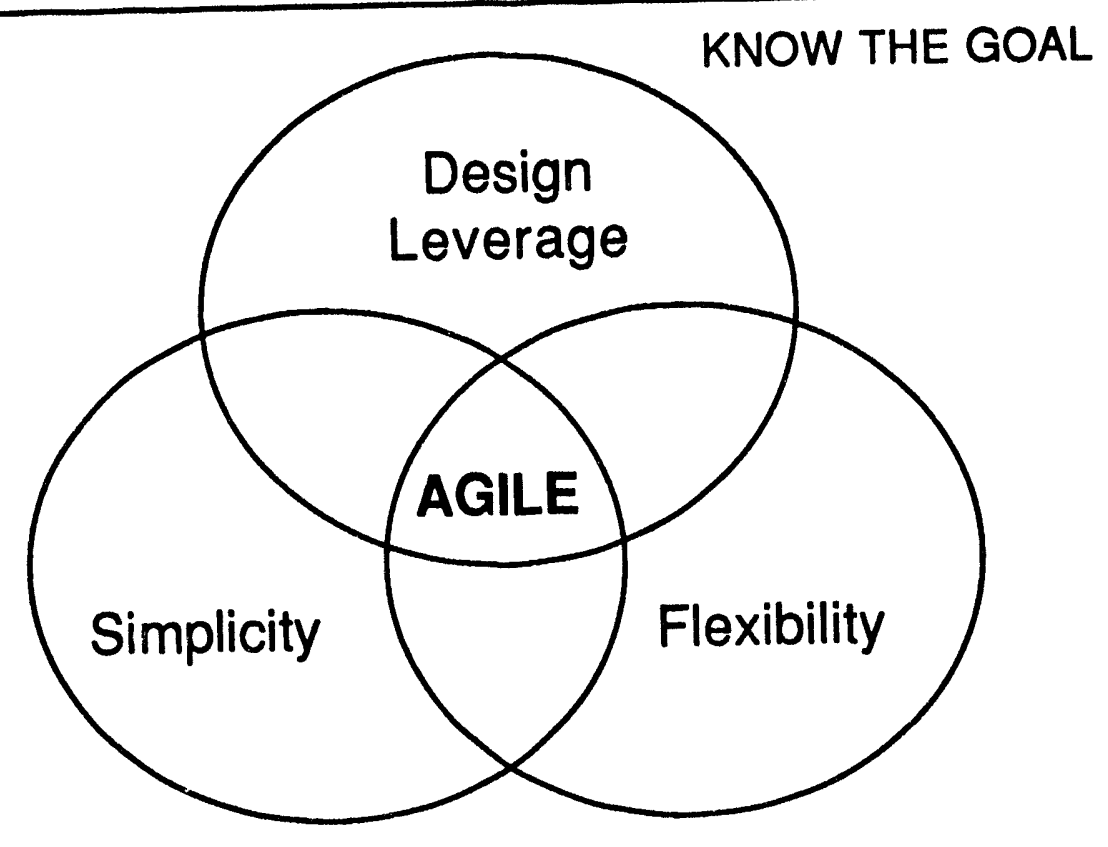

(b)

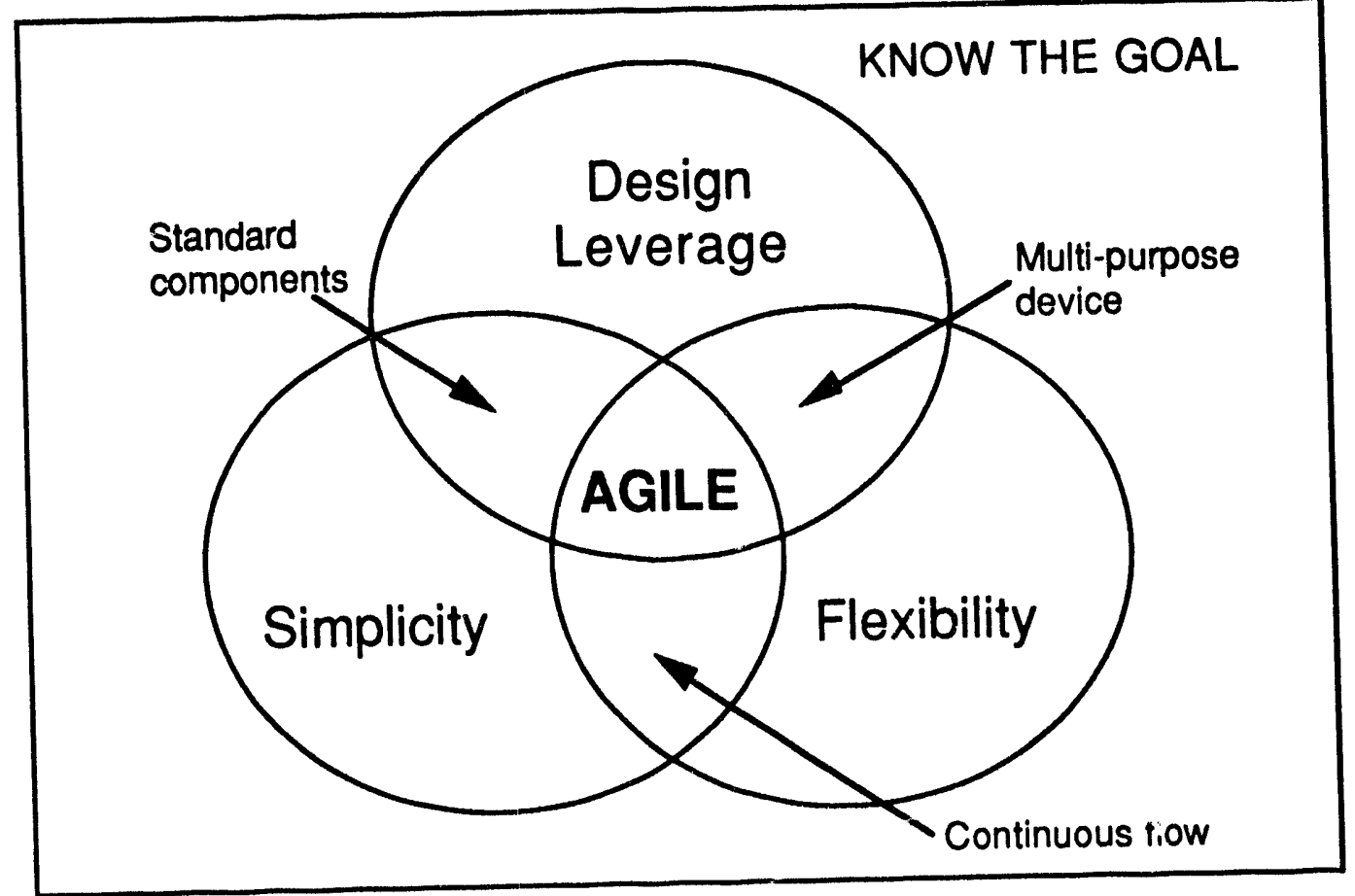




\section{References}

1. Conceptual Design Repert (CDR), for renovation of existing facilities to support Neutron Generators, Cap Assemblies and Power Sources; SNL Project Number CA 60200, Volumes 1 and 2. Sandia National Laboratories, Albuquerque, New Mexico; October 30, 1992.

2. Activity Transfer Plan for Neutron Generators/NTTL, Sandia National Laboratories, Reconfiguration and Neutron Generator Program Management, Org. 5401. [Issue A, March 1, 1993: Issue B, July 19, 1993; Revised August 24, 1993.]

3. Goldratt, Eliyahu M. and Cox, Jeff. The Goal. 2nd revised edition. New York: North River Press, Inc., Croton-on-Hudson, 1992.

4. Schonberger, Richard J. Japanese Manufacturing Techniques: Nine Hidden Lessons in Simplicity. New York: The Free Press, 1982.

5. Infrastructure Team Repert (IDT), submitted by Gerald L. Record, Chairperson, Sandia National Laboratories, Org. 7201. May 19, 1993. 


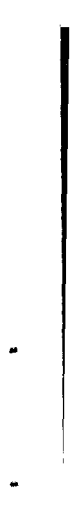




\section{APPENDIX A}

\section{Presentation Briefing Notes}

These briefing notes were from the study group's presentation to the sponsors on May 19, 1993. 


\section{PRESENTATION BRIEFING NOTES}

Neutron Generator Manufacturing Facility

Advanced Manufacturing Study Team

May 19, 1993

NEUTRON GENERATOR MANUFACTURING

FACILITY ADVANCED MANUFACTURING STUDY

1 Challenge: Conduct a short-term study to Identify advanced manufacturing concepts applicable to neutron generator production.

1 Team members:

Ron Stoltz, 8008 Jerry Gurule, 325

Len Beavis, 2471 Rick Harris, 2604

Tom Cutchen, 2506 Paul McKey, 2486

Pablo Garcia, 1671 David Williams, 2304 


\section{STUDY TEAM}

1 Mission Statement: The NGMF Study Team will describe workable pathways by which SNL can Improve its operations and business practices to reduce costs and Increase flexlbility in the NGMF.

\section{Approach:}

- Contact days: 15 contacts days between 4/13 and 5/19/93

- Plant vlsits:

- VARIAN Power Grld \& X-ray Tube Products, San Carlos, CA

- MMSC, Pinellas Plant, Largo, FL

- Review Informatlon: CDR, Activity Transfer Plan, Storyboard, etc.

\section{CONCERNS AND REMEDIES}

\begin{tabular}{|c|c|}
\hline & Concerns: \\
\hline 1 & Unclear statement of work \\
\hline 1 & What are we supposed to do? \\
\hline 1 & Is there an "answer" already \\
\hline 1 & How do we get smartor? \\
\hline 1 & Muttiple customers - multiple answers \\
\hline 1 & Should suggestlons be concrele ve conceptual \\
\hline 1 & Will we have "value-added" \\
\hline 1 & Limited experlence/background in group \\
\hline 1 & Too littio time \\
\hline 1 & Potential for too much retracing \\
\hline 1 & What about record koeping? \\
\hline
\end{tabular}

Remedles:

\section{Rowrtte}

Use misosion statomomt

No

Bring liv others

Identify one customer and multiple stakeholders

Establish "hard vectors"

Use "vectors " to 800

Augment whth documents, vistts, membership

Plck up paco

Don't go back

Keep Informal

May 19, 1993 


\section{PRESENTATION OUTLINE}

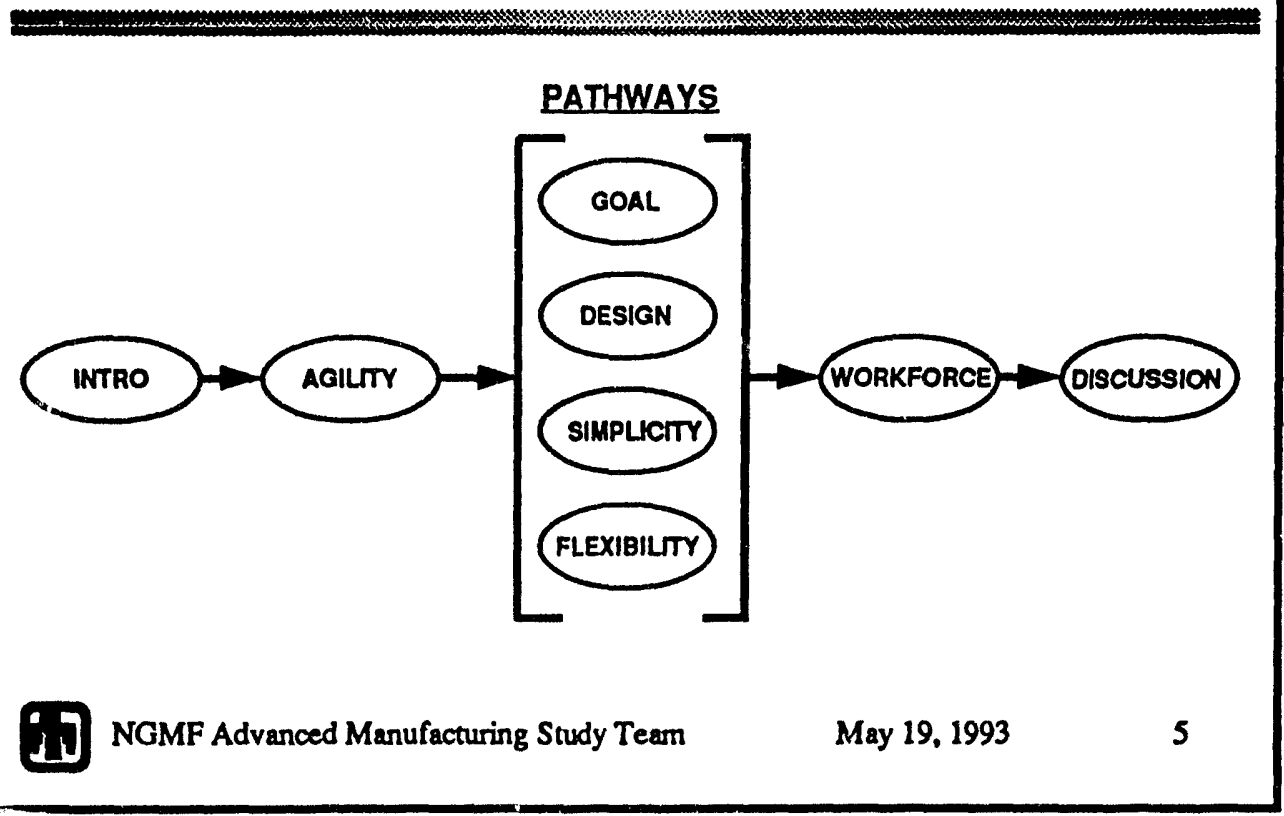

\section{EVOLUTION OF MANUFACTURING PARADIGMS}

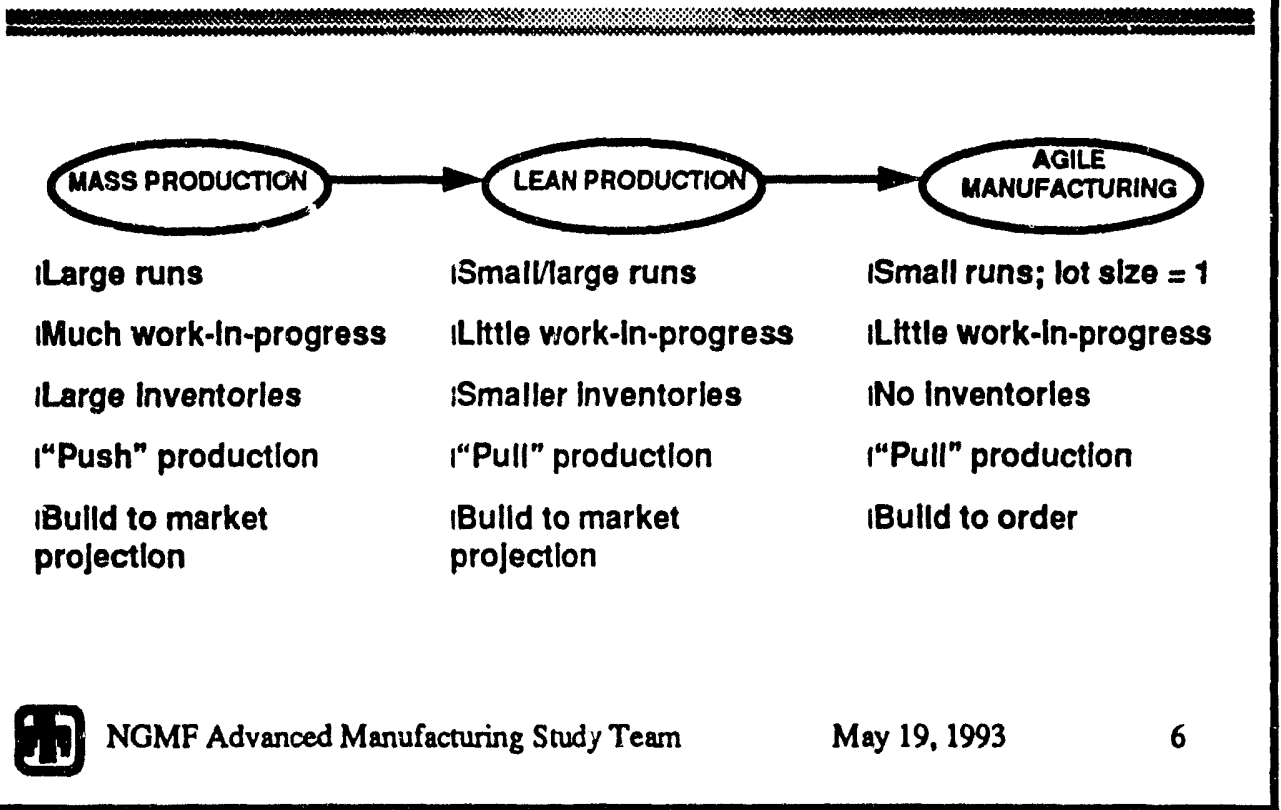




\section{AGILE ENTERPRISE CHARACTERISTICS*}

1 Outside looking in

" Rapid rollout of new products

"Product features evolve through reconfiguration/upgrade

"Relationship with customers are long-term and strategic

"Price paid is based on combined value-added of products, services, and information

- lacocca Inattuw, 1002. Coldman, S. L and Nagel, R. K

Coldent

Management, Vol a, Now. 1/2.

Manas

1] NGMF Advanced Manufacturing Study Team

May 19. 1993

\section{AGILE ENTERPRISE CHARACTERISTICS*}

\section{Inside looking in}

- People, optimally using technology

- Company resources supporting creatlvity of workforce

- Mutual responslbility for success

- Distributed work functions, connected by "groupware" tools

- All declsions made at the point-of-Information

- Flexible production machinery

- Suppllers actlve in product design

- Cooperation among compettors

NGMF Advanced Manufacturing Study Team

- lacocca Inetitute, 1902; Goldman, S. L and Nagel, R N In Int. J. of Technology Management, Vol \&, Noa. 1/2, 


\section{AGILITY BENCHMARK AND SELF ASSESSMENT AREAS*}

I Is product development based on customer criterla of adding value?

1 Do you enhance the impact of people on their ablitty to accompllsh aglie product reallzation?

1 Are company resources leveraged through cooperation with other companies?

I Are you organized to use change and uncertainty as growth opportunftles?

1 Do you incorporate ethical and soclal values in decision making?

\section{ENTERPRISE MANAGEMENT}

\section{THE ENTERPRISE}

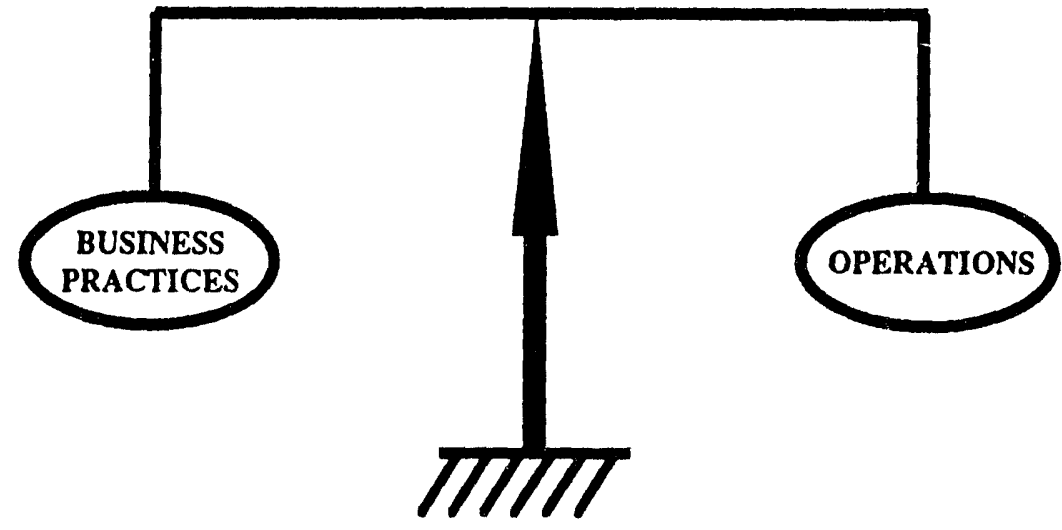



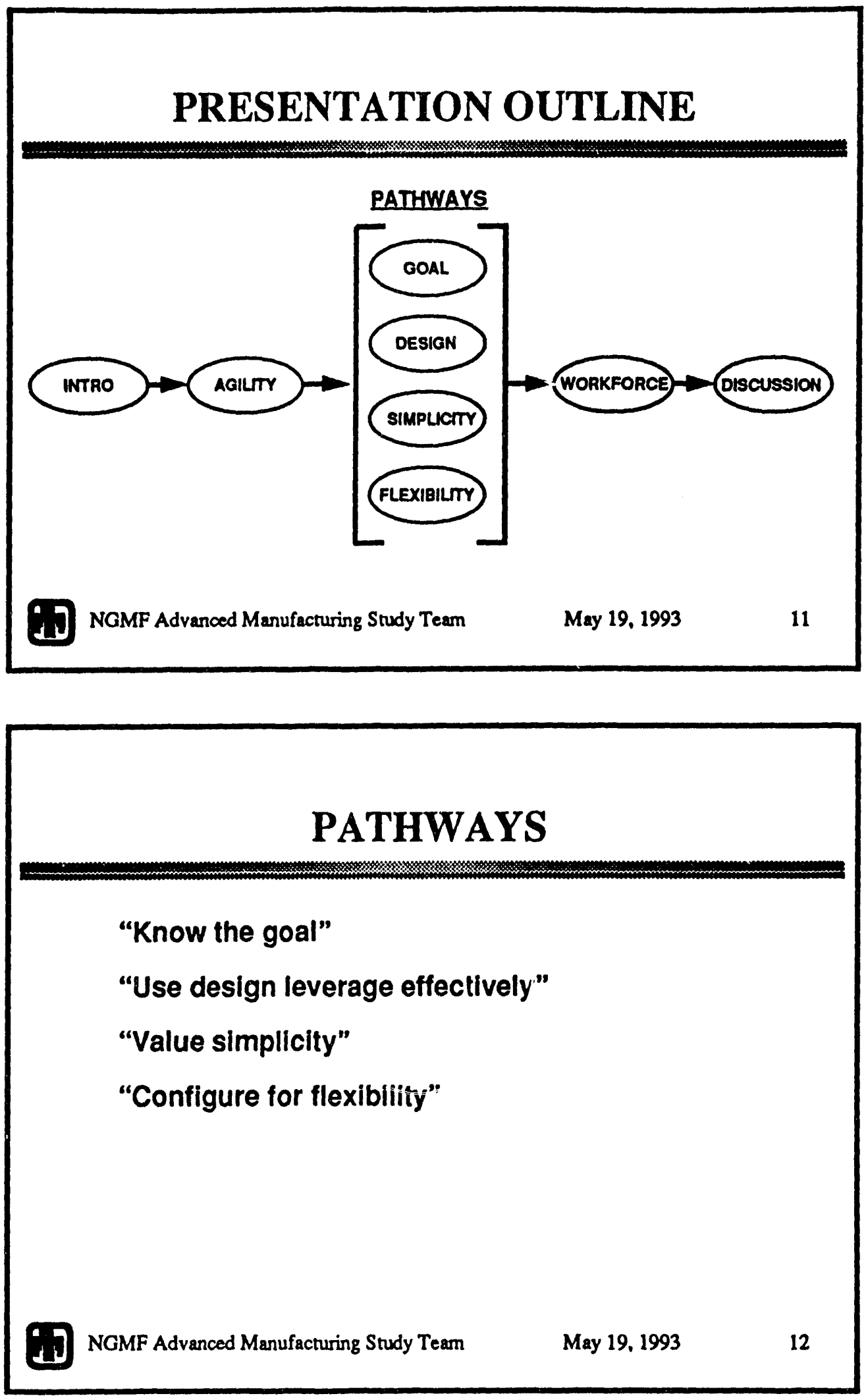


\section{AGILITY}

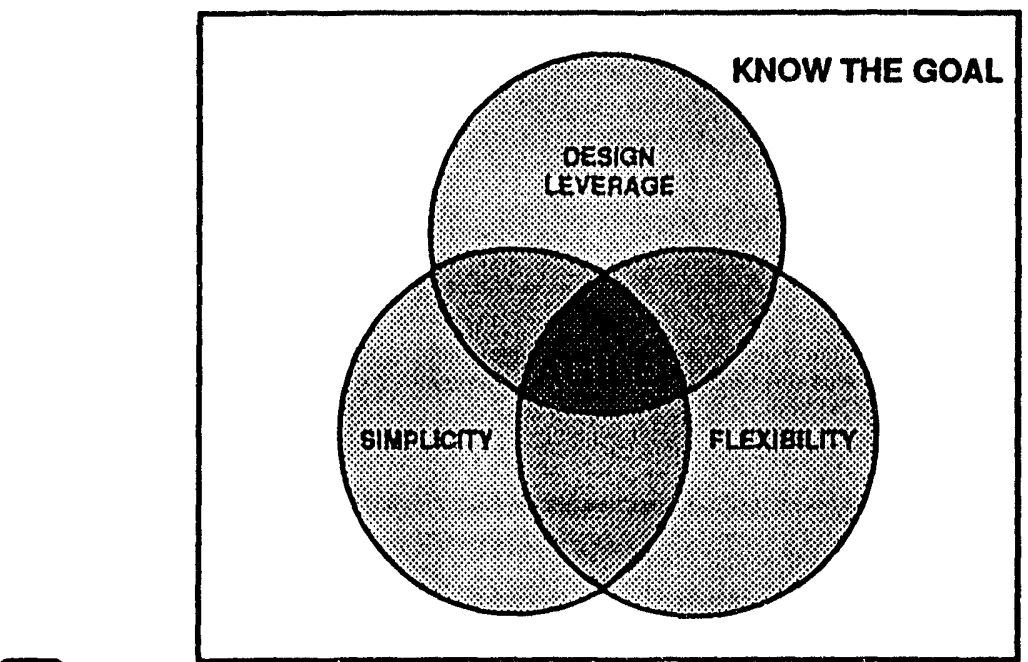

d)

\section{AGILITY}

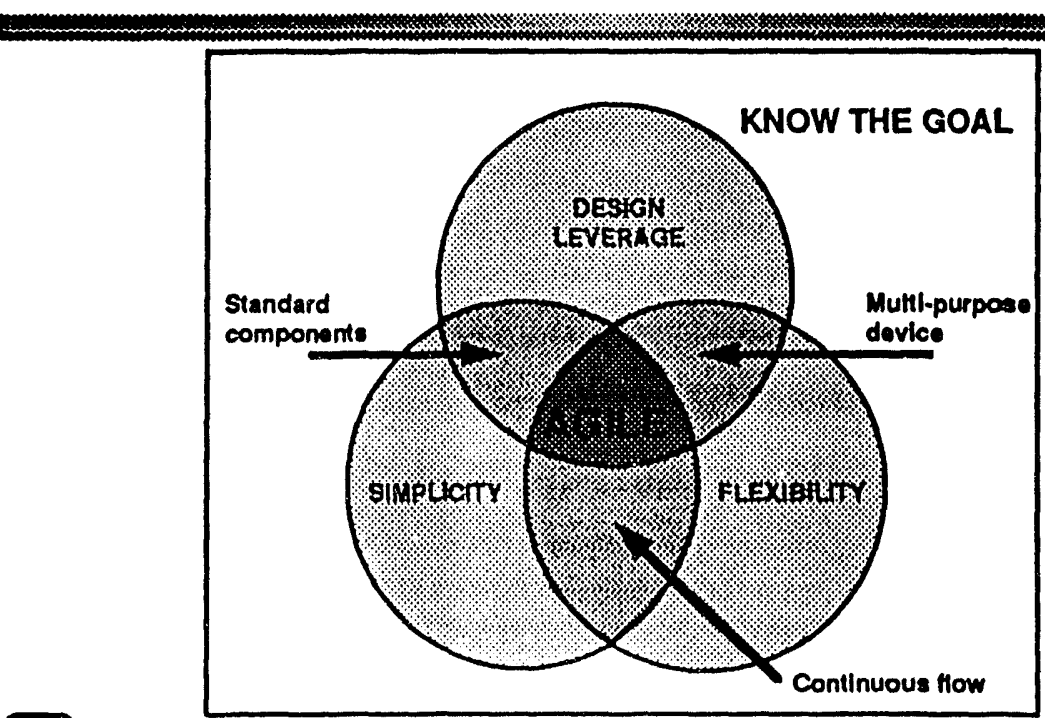




\section{PATHWAYS}

\section{"Know the goal"}

"Use design leverage effectively"

"Value simplicity"

"Configure for flexibility"

\section{KNOW THE GOAL}

I WRITE a single statement of the enterprise's goal

1 Determine which operations and business practices METRICS can be used to MEASURE progress towards the goal

I Establish WRITTEN criteria for decision making 


\section{AN EXAMPLE OF AN EFFECTIVE GOAL}

I Goal

- Operate a commerclal enterprise to make money

1 Metrics

- Throughput

- Inventory

- Operating expense

1 Goal-based decision criteria

- WIII an action SIMULTANEOUSLY

- Increase our throughput?

- Reduce our Inventory?

- Reduce our operating expense?

\section{CONSEQUENCES OF AN INEFFECTIVE GOAL}

I GOAL

- Operate a for-proflt commerclal enterprlse to PRODUCE goods

I CONSEQUENCES

- Inapproprlate metrics

- Etficiency

- Full utillzation

LESSON AVOID LOCAL OPTIMIZATION

- Seek local optimums

- Unintended results

- Warehouse Inventorles Increase

- Quality can suffer through error propagation

- Loss of plant aglilty by not focusing on reduced set-up tImes

NGMF Advanced Manufacturing Study Team

May 19, 1993 


\section{A SANDIA EXAMPLE}

I Goal

\section{(We don't know if this is THE goal)}

- Operate a facility of natlonal strategic Importance for the fabrication of neutron generators and switch tubes at a minimum tetal cost.

\section{Metrics}

- Total cost

- Product performance

- Schedule varlance

\section{SAMPLE APPLICATION CRITERIA:}

\section{Proposed action}

- Should we purchase subassemblles In an effort to reduce the number of operations we must support in our facllity?

\section{Goal-based decision criteria}

- WIII this action SIMULTANEOUSLY

- Reduce total cost?

- Improve product performance?

- Reduce schedule varlance?

\section{Approach}

- Evaluate on the basis of SIMULTANEOUS Impact on the METRICS 


\section{PATHWAYS}

"Know the goal"

\section{"Use design leverage effectively"}

"Value simplicity"

"Configure for flexibility"

\section{PRODUCT DESIGN LEVERAGES PRODUCTION COST}

\section{PRODUCTION}

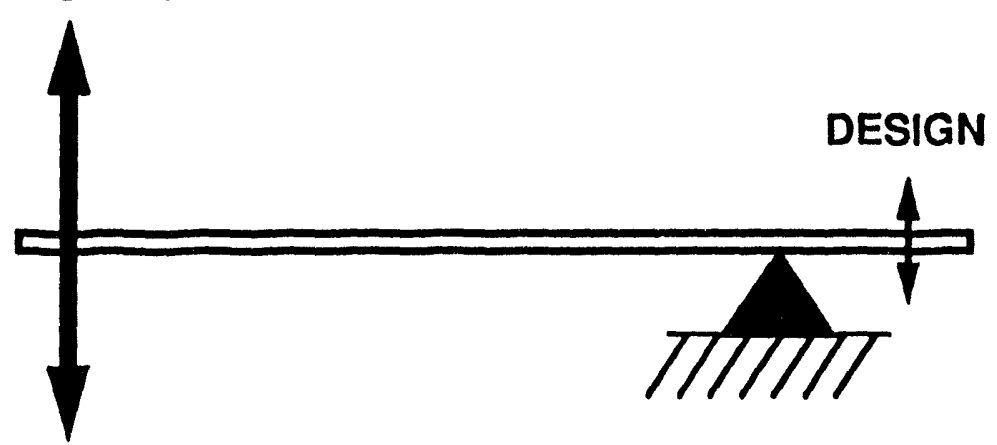




\section{USE DESIGN LEVERAGE EFFECTIVELY}

I Maintain design stablilty and discipline

I When change is required, use Concurrent Englneering and Design for Manufacturability

I Use simplicity: keep only essential specifications and use industrial specifications where possible

I Seek commonality of plece parts and processes for switch tubes, neutron tubes, and neutron generators

- j NGMF Advanced Manufacturing Study Team

\section{PATHWAYS}

"Know the goal"

"Use design leverage effectively"

\section{"Value simplicity"}

"Configure for flexibility" 


\section{VALUE SIMPLICITY}

IWorkforce

IQuallty

IProcess
IProcurement

IPlece parts

IFacilities

\section{SIMPLICITY EMBRACES}

\section{Workforce}

- Use one workforce for prototype, development, and manufacturing

- Use one workforce for tubes and generators

- Minimize levels of management

1 Quality

- Simplify means of achloving QC1 objectives

- Eliminate dedicated In-process Inspectors 


\section{SIMPLICITY EMBRACES, cont.}

1 Processes

- Standardize common processes

- Ellminate non-value added processes

- Use same processes for prototype, development, and manufacturing

- Use simple conilguration management for Ols

- Enhanco Ols with graphlcs

1 Procurement

- Use source-accepted parts and materlals from qualliled vendors

\section{SIMPLICITY EMBRACES, cont.}

\section{Plece parts}

- Use the minimum number of plece parts per component

- Use common plece parts from component to component where possible

- Use "push" or "pull" llow as approprlate

\section{Facillitles}

- Use common equipment for prototype, development, and manufacturing

- Configure facility for optimum product flow

- Automated controls must be simple to setup and operate 


\section{PATHWAYS}

"Know the goal"

"Use design leverage effectively"

"Value simplicity"

\section{"Configure for flexibility"}

1. NGMF Advanced Manufacturing Study Team

\section{CONFIGURE FOR FLEXIBILITY}

I Management

1 Quality

I Automation 


\section{FLEXIBILITY IN MANAGEMENT}

1 Diversify the products and anticipate customer needs

1 Reduce in-process inventory to minimize defects and scrap

I Configure facility to support flexibility in operations

\section{FLEXIBILITY IN QUALITY}

1 Give the workers the responsibility and ownership of Quality

1 Use acceptance testing as a confirmation test rather than as means for assessing the Quality of the product

1 Use common process line for development, prototype, and production with graded rigor

1 Use the same calibrated equipment for development and production. 


\section{FLEXIBILITY IN AUTOMATION}

I Evolve a flexible and unified communications system.

1 Establish a written automation policy.

- Automate only to achleve the goal

- Don't become enamored with technology

\section{PRESENTATION OUTLINE}

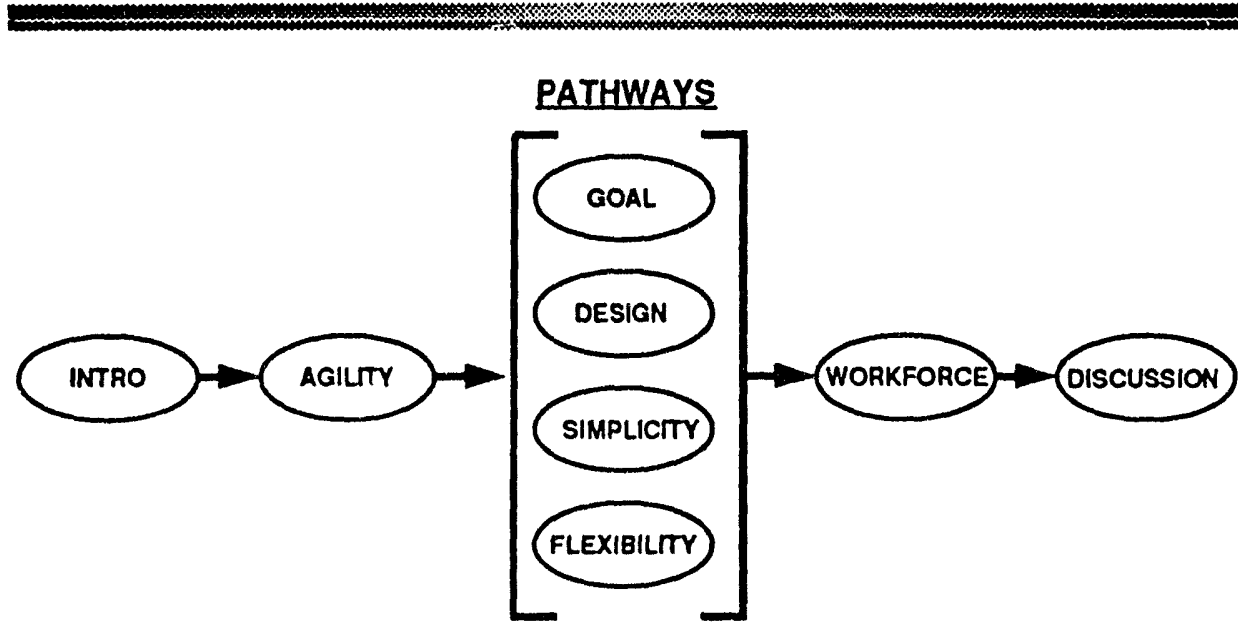




\section{THE WORKFORCE}

I The workforce is the combined management, engineering, support, and production team

I The workforce is the means by which Sandia achieves its goals

\section{WE NEED AN OWNERSHIP ENVIRONMENT}

1 Where workgroups control and improve their product

1 Where all team members have authoriły and responsibility to "stop the line"

I Where workers author and improve their operating instructions 


\section{WE NEED A LEARNING ENVIRONMENT}

I Where skills Improvement is ongoing

I Where skills and knowledge match job requirements

1 Where cross training is a way of life

1 Where outside ideas and practices are considered valuable

\section{WE NEED A SUPPORTIVE ENVIRONMENT}

I Where workers are encouraged to be creative and to take initiative

1 Where mutual respect is evident

1 Where the workplace is pleasant and positive 


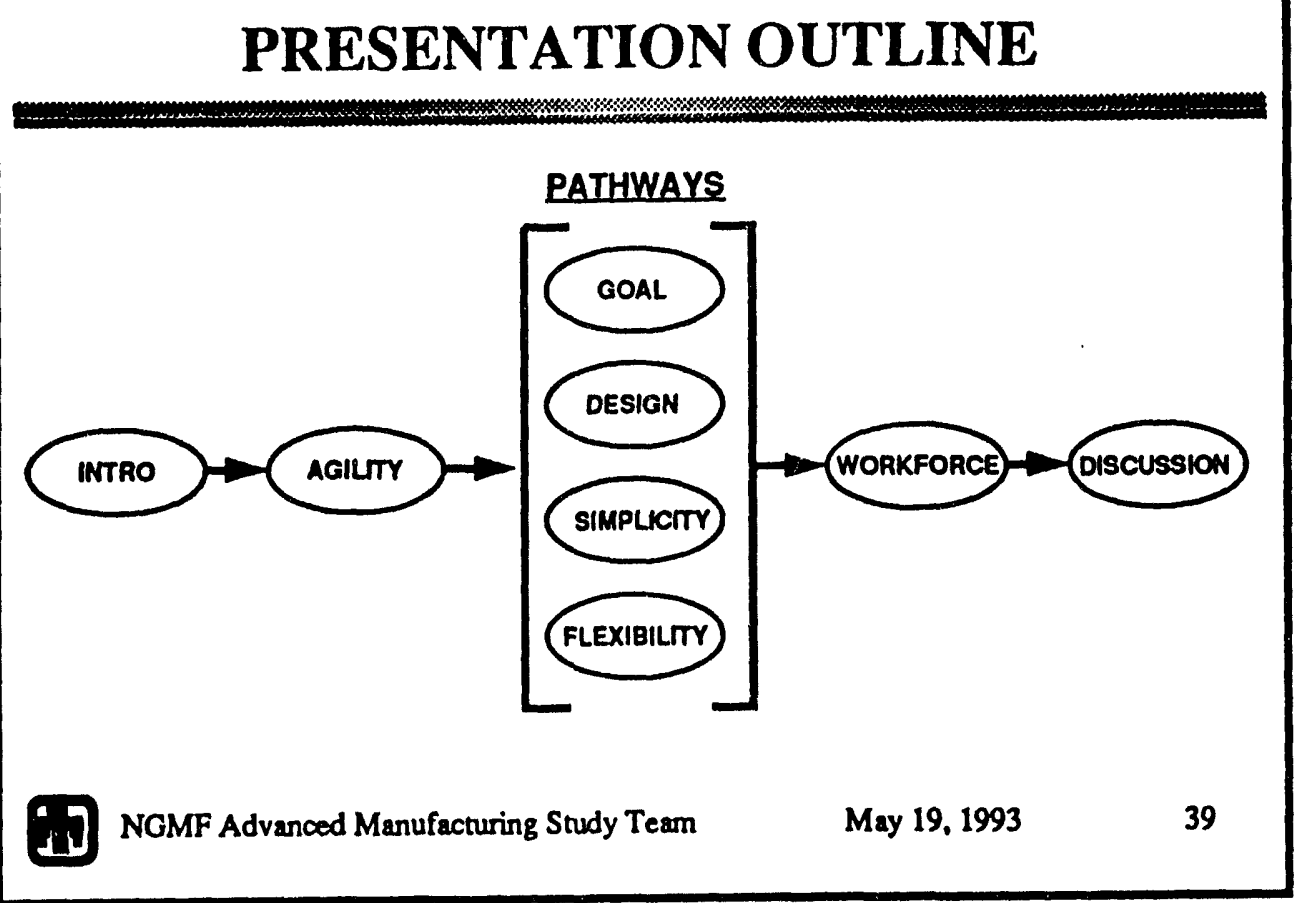

\section{PATHWAYS}

"Know the goal"

"Use design leverage effectively"

"Value simplicity"

"Configure fọ flexibility" 


\section{OUR MISSION STATEMENT}

I The NGMF Study Team will describe workable pathways by which SNL can improve its operations and business practices to reduce costs and increase flexibility in the NGMF.

\section{RECOMMENDATION}

I These pathways should be used as guidelines for the establishment and operation of the Neutron Generator Manufacturing Facility at Sandia. 


\section{NEUTRON GENERATOR MANUFACTURING FACILITY}

1 Manufacturing and development operations

w In a common facility

„Using same staff

"With graded rigor

\section{NOT A FACTORY!}

\section{DISCUSSION QUESTION \#1}

1 Is the goal of the NGMF enterprise to:

- produce 500 NG/yr (plus speclalty components) at a minimum total cost?

or

- establlsh manufacturlng system credlbllity with US Industry?

or

- be a platform to incubate advanced manufacturing concepts?

or

- spearhead the transformation of Sandla to a new culture?

or

- be a world-class example of explolting high technology in manufacturlng?

or ...

1] NGMF Advanced Manufacturing Study Team

May 19, 1993 


\section{DISCUSSION QUESTION \#2}

1 How about merging all DOE funding streams (R\&D, SS, Reconfiguration, etc.) to manage the Neutron Generator Program as a single and comprehensive national capability? 


\section{APPENDIX B}

\section{Quotes and Observations}

The material in this Appendix is a collection of quotes and observations from individual members of the NGMF Advanced Manufacturing Study Team. It represents a selected cross section of individual views, opinions, and observations garnered as a result of visits and discussions by the team and its members while carrying out this study. Although each observation or quote does not necessarily represent the unanimous view of the entire team, they are all valued by the team as "Keepers," and they have all played an important role in team discussions and the evolution of consensus views. We believe these "Quotes and Observations" have decision-making value, and will be of interest those responsible for the NGMF. 


\section{QUOTES AND OBSERVATIONS: "KEEPERS"}

NGMF Advanced Manufacturing Study Team May 19, 1993 


\section{"KEEPERS"}

1. Minimize Computers

- Use goal-based decision-making criteria for capital procurement.

- At Pinellas, computers became self-serving; they have driven tremendous increases in personnel.

- "Pinellas engineers whose job is to support the floor tend to sit at their desks and consult computers instead of going to the floor to address problems." (Floor Manager, Pinellas)

- Data need not be entered into computers at each workstation. Consider entering product data at key points during processing and at build completion.

\section{Cross-Train the Work Force}

- Hire and encourage technician-level staff for fabrication with an aptitude for highly-skilled cross-functional operations.

- Use technicians to enhance agility and flexibility, and ensure a flexible work-assignment process.

- Agility is proportional to the competency of the operator.

- It is important that people understand their role in the operations, and how their work impacts others. 
- Budget for hardware/materials to support cross-training, even if it will not yield product to shipment.

- In the Pinellas JTA area in 1990 , the staff built 2500 units of 28 different designs to Diamond-Stamp quality with 12 people, including a QAS-2 survey.

- "If I had your job to do, I would do it in the (PP) JTAlike environment." (Product Engineer, Pinellas)

3. Quality Is Visible

- Push quality down (to operator) and out (to vendor).

- Operators should carry out in-process inspections.

- "The quality of the product is determined by the operator." (a PP manager)

- At Varian, the goal is to have a single plant-level quality inspector, who will train the operators to carry out all inspections.

- SPC control charts should be visibly evident and maintained manually by the operators for effectiveness and impact, unless they are comfortable with and routinely use computers in their operations.

- "There are many DOEs, each interpreting QC-1 in different ways." (Manager, Pinellas) 


\section{Use Effective Operator Instructions (OIs)}

- Operators should author OIs.

- State the purpose of the OI clearly at the top of the document.

- Include guidance in the OI on how the operator will know that the process has been done right.

- OIs should include graphics when appropriate.

- Ensure that the flow tags for products include the proper OI revision number.

- Use OIs on computer terminals and use a software system (SHERPA?) that will highlight OI changes.

- "Technicians should do the work using less-detailed OIs."

5. Use "Push" and "Pull" Appropriately

- "Pull" = JIT = DFT $($ Demand Flow Technology $)$

- "Push" = Traditional Batch-Flow Processing

- Use "Pull" for production, "Push" for development/specialty units. (Varian)

- Example of local "Pull" operation = Pinellas Continuous-Flow Process 
- Kanban processes are used to improve throughput, reduce work-in-process inventory, and protect against propagated errors. (Varian, Pinellas)

- "Have plenty of inventory, at least 1.5 cycles ahead. JIT causes us to miss schedule." (Manager, Pinellas)

\section{Establish a Product Flow Diagram Early}

- "The Product Flow Diagram drives needed equipment, tooling, gauges, processes, quality plan, OI Index, and location for each processing operation. This document is key." (Manager, Pinellas)

- The PFD should be developed for the tubes and generator, then used as the basis for optimizing the Building 870 layout during Titles I and II.

- Optimum process flow is achieved when each process step has only one dependency (feed point) in the PFD. (Varian)

7. Operations - Build A Peninsula, Not An Island

- Utilize and depend on existing SNL facilities and infrastructure where possible.

- Physical interaction with scheduling boards, charts and paper travelers may provide the operators with a sense of motion and control within the process that would be lost by using computers.

- Consider using the Green-Amber-Red Light System (Varian) or an analog of it. 
- Will need a system to convert DOE UU requirements to a component build schedule.

8. Use Automation Appropriately

- Don't automate unless it improves a process and eliminates a person. (Varian)

- Appropriate use of automation enhances flexibility. Inappropriate use limits flexibility.

- "Get it (the process) simple before getting fancy." (Varian)

9. Use Good Metrics

- Choose a minimal, but significant set of relevant metrics that support the goal.

- Standardize metrics for all work groups as much as possible (\#MRBs, schedule deviation, ...).

- Don't overkill the metrics. Use balance and prioritize.

10. Manage the Materials Operations Carefully

- Make/buy decisions should be a formal, written process.

- Minimize special materials early, at the design stage.

- Characterize processes and materials. 
- "Material control and identification against the OIs-tracking WR vs. Development--that will be Sandia's biggest problem, not Product Flow." (Manager, Pinellas)

\section{Use A Simple Database/Flow Control System}

- Take a good market survey and purchase up-to-date computer tools. (Manager, Pinellas)

- Keep information on a relational database in one system. (Two Managers, Pinellas)

- Maintain a process-data database for Process Control Engineers.

- Shop Floor Control software establishes a Build Routing, which covers all sequences and documents, including the traveler or flow tag. (Pinellas)

- Use MRP/MRP2 system only if it meets the goal for the facility.

- We don't need a "full-blown" computer control system.

- "Would not use MRP. Use Shop Floor Control." (Manager, Pinellas)

- "Would not do the job without MRP." (Engineer, Pinellas)

- Shop Floor Control is not used in JTA Operations, because the entire job is done in one area." (Manager, Pinellas) 


\section{Work-Area Security is Required}

- The work area for SRD components must be designed to permit workers to leave the area (breaks, lunch, etc.), with work items left in work-in-progress state.

\section{Make It a Virtual Enterprise}

- Use Sandia as the final assembler in a virtual manufacturing enterprise.

- A virtual enterprise will enable manufacturing expertise yet allow Sandia to focus on manufacturing technology.

14. Manage In Tune With Goals and Purpose

- Obtain an experienced manager from outside to run the manufacturing operations.

- There are 2 factories--the one we see and the "hidden" factory (rework, unnecessary operations, ...). Know and manage both!

- First-level managers should have hands-on experience and/or capability in their areas of responsibility.

- Everyone (operators, middle and top management) needs to be "in sync". 


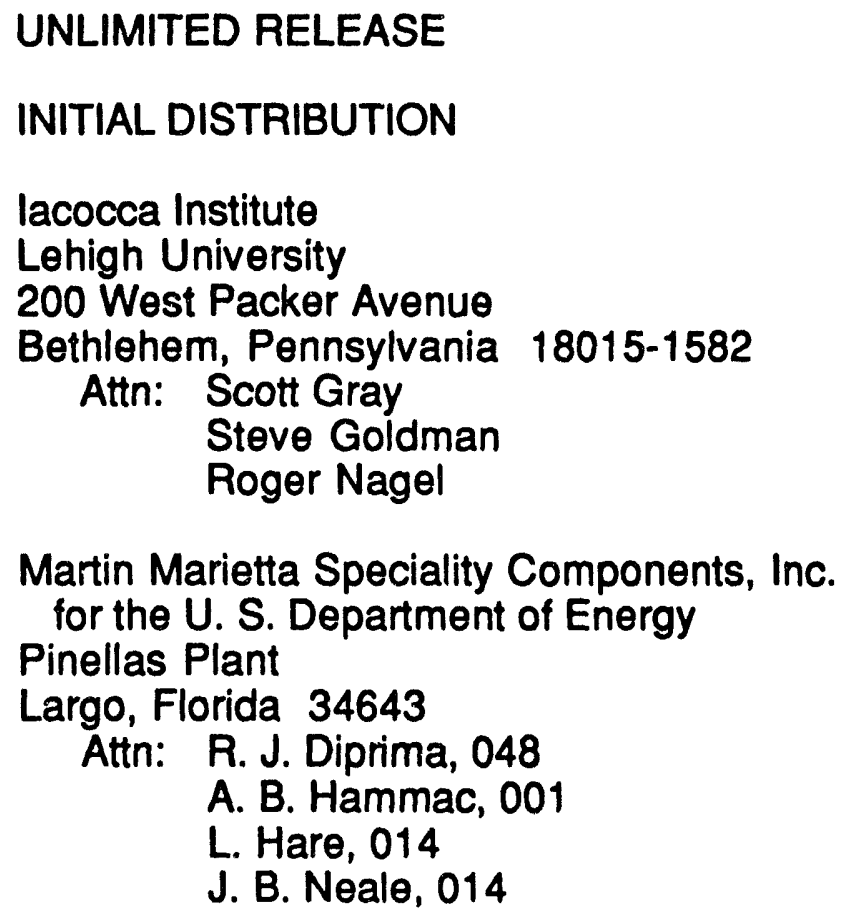

Martin Marietta Speciality Components, Inc.

for the U. S. Department of Energy

Pinellas Plant

Largo, Florida 34643

Attn: R. J. Diprima, 048

A. B. Hammac, 001

L. Hare, 014

J. B. Neale, 014

U. S. Department of Energy

Albuquerque Operations Office

Albuquerque, New Mexico, 87115

Attn: C. R. Loeber, WQD

MS0319 R. N. Harris, 2604 (5)

MS0322 P. J. Eicker, 2100

MS0429 W. C. Nickell, 5100

MS0471 M. W. Callahan, 5092

MS0473 H. J. Saxton, 5400 (5)

MS0507 R. A. David, 2700

MS0509 D. W. Williams, 2304 (5)

MS0509 R. D. Andreas, 2300

MS0511 G. N. Beeler, 2500 (10)

MS0513 H. W. Schmitt, 2000

MS0515 F. M. Bacon, 2561 (5)

MS0516 R. A. Damerow, 2564 (5)

MS0517 D. W. Doak, 2010

MS0522 A. K. Jacobson, 2503

MS0522 R. B. Diegle, 2502

MS0563 P. C. McKey, 2486 (5)

MS0630 J. Jones, 2800

MS0638 G. A. Gurule, 12326 (5)

MS0871 J. B. Woodard, 5402

MS0871 J. E. Gronager, 5401 (5)

MS0872 G. M. Ferguson, 5408 


$\begin{array}{ll}\text { MS0872 } & \text { R. B. Muniz, } 5404 \\ \text { MS0953 } & \text { W. E. Alzheimer, } 2900 \\ \text { MS0955 } & \text { T. J. Young, 2901 } \\ \text { MS0959 } & \text { F. Gerstle, Jr., 2476 } \\ \text { MS0960 } & \text { J. W. Search, 2400 } \\ \text { MS0985 } & \text { J. H. Stichman, 2600 } \\ \text { MS1007 } & \text { P. Garcia, 2171 (5) } \\ \text { MS1066 } & \text { G. L. Record, 7201 } \\ \text { MS1070 } & \text { K. R. Grothaus, 2222 } \\ \text { MS1070 } & \text { R. E. Bair, 2200 } \\ \text { MS2501 } & \text { L. C. Beavis, 2566 (5) } \\ \text { MS2501 } & \text { L. E. Pope, 2566 (5) } \\ \text { MS2501 } & \text { P. J. Wilson, 2565 (5) } \\ \text { MS2521 } & \text { G. R. Reif, 2506 } \\ \text { MS2521 } & \text { J. T. Cutchen, 2506 (5) } \\ \text { MS9001 } & \text { J. C. Crawford, 8000; Attn: } \\ & \text { D. L. Crawtord, 1900 } \\ & \text { M. E. John, 8100 } \\ & \text { R. J. Detry, 8200 } \\ & \text { M. J. McLean, 8300 } \\ & \text { P. E. Brewer, 8500 } \\ \text { MS9005 } & \text { J. A. West, } 8600 \\ \text { MS9006 } & \text { E. E. Ivesh, 5200 } 5 \\ \text { MS9105 } & \text { L. A. Hiles, 8400 } \\ \text { MS9401 } & \text { R. C. Wayne, 8700; Attn: } \\ & \text { D. L. Lindner, 5605 } \\ & \text { M. W. Perra, 8714 } \\ & \text { J. M. Hruby, 8716 } \\ \text { M. L. Callabresi, 8743 } \\ \text { MS9405 } & \text { R. E. Stoltz, 8008 (5) } \\ \text { MS } 9021 & \text { Technical Communications for OSTI (10) } \\ \text { MS } 9021 & \text { Technical Communications/Technical } \\ \text { MS } 0899 & \text { Technical Library Processes (4) } \\ \text { MS } 9018 & \text { Central Technical Files, MS9018 (3) } \\ & \end{array}$



